\title{
The potential and challenges of Health 4.0 to face COVID-19 pandemic: a rapid review
}

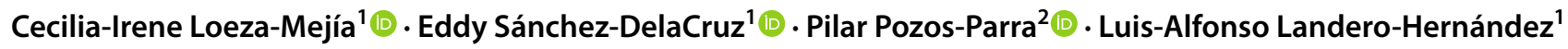

Received: 24 June 2021 / Accepted: 14 September 2021 / Published online: 28 September 2021

(c) IUPESM and Springer-Verlag GmbH Germany, part of Springer Nature 2021

\begin{abstract}
The COVID-19 pandemic has generated the need to evolve health services to reduce the risk of contagion and promote a collaborative environment even remotely. Advances in Industry 4.0, including the internet of things, mobile networks, cloud computing, and artificial intelligence make Health 4.0 possible to connect patients with healthcare professionals. Hence, the focus of this work is analyzing the potentiality, and challenges of state-of-the-art Health 4.0 applications to face the COVID19 pandemic including augmented environments, diagnosis of the virus, forecasts, medical robotics, and remote clinical services. It is concluded that Health 4.0 can be applied in the prevention of contagion, improve diagnosis, promote virtual learning environments, and offer remote services. However, there are still ethical, technical, security, and legal challenges to be addressed. Additionally, more imaging datasets for COVID-19 detection need to be made available to the scientific community. Working in the areas of opportunity will help to address the new normal. Likewise, Health 4.0 can be applied not only in the COVID-19 pandemic, but also in future global viruses and natural disasters.
\end{abstract}

Keywords Health 4.0 COVID-19 $\cdot$ Artificial Intelligence $\cdot$ Machine learning $\cdot$ Remote clinical services $\cdot$ Communication networks

\section{Introduction}

The new coronavirus (COVID-19) appeared in Wuhan, China in 2019, and subsequently, it was declared a global emergency by the World Health Organization [1]. The COVID-19 emergency brought global challenges in industry [2-4], education [5], politics [6], economy [2, 6, 7], tourism [7], and health [5-12] services. Being one of the most important health $[6,13]$, having a fundamental role in the COVID-19 response [9] due COVID-19 pandemic is considered the first global health crisis in the digital age [10]. COVID-19 produces high rates of contagion in the population and medical staff $[2,10,12,14,15]$, high spread rate

This article is part of the COVID-19 Health Technology: Design, Regulation, Management, Assessment

Eddy Sánchez-DelaCruz

eddsacx@gmail.com

1 National Technological, Misantla Campus, Veracruz, Mexico

2 Universidad Autónoma de Baja California, California, Mexico
[16-18], and high number of deaths [14] including medical personnel [7, 12].

The COVID-19 virus has a long incubation period that even people can be infected without showing symptoms [2]. Therefore, worldwide restrictions have been applied, such as flight limitations [16, 19], reduce or suspend public transportation [20], social distancing [7], cancellation of mass events [3], regulations on business operation [3], and partial or strict lockdown $[10,15,16,19,21-23]$. For all the above, the pandemic has affected people's lifestyles [7] and routine medical procedures [11]. Likewise, there is a need in offering remote services due to the most susceptible population, suffering from diseases such as hypertension, cancer, and diabetes. In addition, it is considered that if advanced infrastructure is lacking in times of a pandemic, the pandemic will not be controlled and in the future, another type of virus could affect society [12]. Thus, technological trends are considered key to improve healthcare [24] and face the COVID19 pandemic [7]. Hence, various proposals in the literature have emerged to fight against COVID-19, including Industry $4.0[4,25]$ which is a trend of automation and information exchange that continually evolves in various sectors of the 


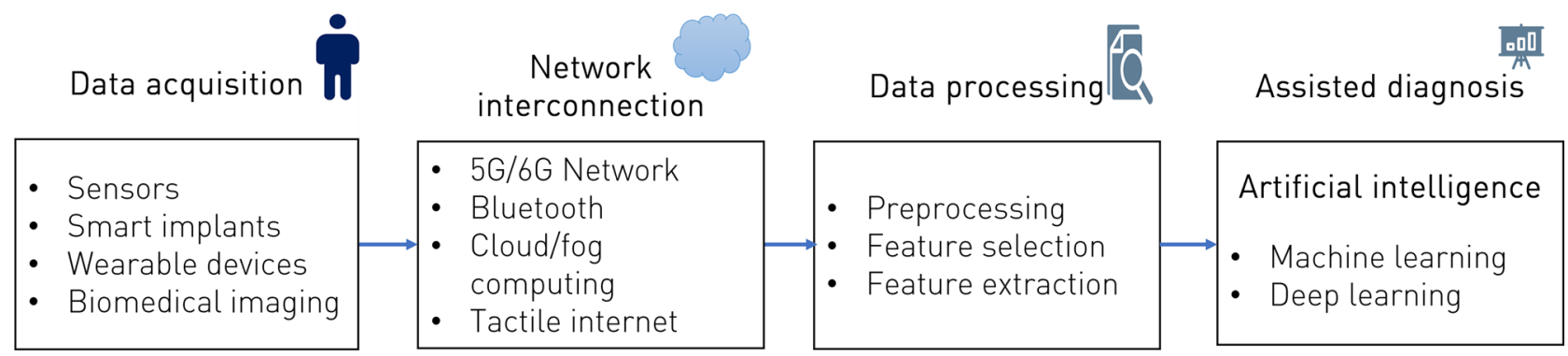

Fig. 1 Health 4.0 pipeline for assisted diagnosis

population and industries, allowing the development of more flexible and efficient processes and services.

Motivated by the success of revolution 4.0, Health 4.0 is developed, which focuses on the patient [24] and integrates services such as cloud/fog computing [26-30], big data [15, 26, 28], 5G network [7, 23, 27, 31, 32], 6G network [12], blockchain [33], and Internet of Things (IoT) [26-29, 31, 34]. Further, 2021 was forecast to be the year that focuses on health systems [33]. Hence, the contribution of this review is analyzing the potential and challenges of state-of-the-art Health 4.0 applications including assisted diagnosis, augmented environments, forecasts of COVID-19, medical robotics, and remote clinical services to face the COVID-19 pandemic.

In order to search for relevant works, the following keywords were used: «COVID-19», «health 4.0», «health care», «pandemic», «artificial intelligence», «machine learning», «deep learning» and «internet of things». In the studies previously located, a manual search was carried out in the located scientific papers, as follows: the cited works that were similar by title were analyzed and then the same was done with those similar. Studies from scientific database ${ }^{1}$ and a search engine $^{2}$, were included: articles, reviews, and viewpoints.

The rest of this work is organized as follows, Sect. 2 reviews the medical tasks in Health 4.0 that can be performed, including assisted diagnosis (subsection 2.1), augmented environments (subsection 2.2), forecasts of COVID-19 (subsection 2.3), medical robotics (subsection 2.4), and remote clinical services (subsection 2.5). Section 3 exposes scopes of Health 4.0, while in Sect. 4 the challenges are presented. In addition, Sect. 5 includes conclusions and future work.

\section{Medical tasks}

\subsection{Assisted diagnosis}

Assisted diagnosis helps to receive proper treatment in time [35]. Research has reported that artificial intelligence (AI)

\footnotetext{
${ }^{1}$ ScienceDirect and IEEE Explore

2 Google Scholar
}

and machine learning help to develop decision support systems. They can even surpass the finding of correct diagnosis compared with physicians [36] mainly in pathologies using images [35]. Automatic diagnosis can be performed by integrating AI algorithms with applications in cloud/ fog computing [36] allowing portability and data analysis from anywhere [29, 36] through different IoT devices [30]. In addition, automatic diagnosis is especially useful when there is a lack of specialized physicians [37].

Figure 1 depicts the general Health 4.0 pipeline for assisted diagnosis, involving data acquisition, network interconnection, data processing and assisted diagnosis. Patient data comes from different sources, including smart implants, sensors, and biomedical images. Data is collected through different computer networks. Heterogeneous data processing is done using preprocessing, selection, and feature extraction techniques. Finally, the assisted diagnosis is carried out by $\mathrm{AI}$ techniques mainly machine learning and deep learning.

\subsection{Augmented environments}

Strict quarantine makes learning difficult, so Augmented Reality (AR) and Virtual Reality (VR) can be used [25]. AR and VR are novel ways to explore medical conditions [38] and enhancing visual diagnosis [39]. VR can help to explore the COVID-19 virus in a three-dimensional way [23]. Also, it can be applied for teaching (i.e. anatomy, dermatology [39], nursing [38] physiotherapy [40]), procedure planning (i.e. dermatology [39], maxillofacial [41]), lesion tracking (i.e. dermatology [39]), simulation and procedural training [38] such as the training of physicians in orthopedics and surgery $[34,41]$. Balian et al. analyzed the feasibility of a training system that uses AR to simulate cardiopulmonary resuscitation, where $98 \%$ of study participants recognized that visualization helps training [42]. Likewise, Kelly et al. concluded that clinical reasoning strategies can be made explicit when AR is used [40]. Further, computer vision applied in AR and VR allows to obtain, process, analyze and understand images and videos [43], hence, computers can understand the context of the physical world. Also, the application of 
$\mathrm{AI}$ in AR allows the automatic recognition of objects [43]. Therefore, AI and computer vision can be applied to improve the experience of health care providers and offer personalized environments for clinical teaching. Health 4.0 allows connecting the physical and virtual worlds [44].

\subsection{Forecasts of COVID-19}

Forecasting models furnish valuable quantitative information and help to make decisions in the short-term [45]. Hence, forecasting models can help to prevent the spread of COVID-19 and assign medical supplies [45]. Machine learning and deep learning can predict outbreaks of COVID-19 $[25,46,47]$, and discover disease trajectories in geographic zones [48]. Also, machine learning and deep learning can predict COVID-19 cases [3, 23, 49-52], deaths [50] and recovered cases [50]. In addition, forecasts have allowed the generation of COVID-19 spread maps and dashboards [17]. Further, using mobile geographic information systems (GIS), tracking of COVID-19 in near-real-time can be carried out [17]. Likewise, natural language processing (NLP) helps to carry out translations of mapping dashboards into various languages [17]. In Fig. 2, we present an illustrative example of a layout of COVID-19 forecasts.

\subsection{Medical robotics}

Robots are machine-based agents that interact with the environment and can be adapted to perform certain tasks [14]. Medical robots can assist in various tasks such as treatment of patients [34], surgery, and recognition of surgical activities. Robot-assisted surgery provides advantages like minimal invasiveness [53], better vision, and better instrument control [54-56], thereby allowing its application in difficult environmental conditions [34] and facilitating complex surgeries [57].

Recently, an increase in robotic-assisted surgery has been observed, showing applications such as radical prostatectomy [55], radiosurgery of gastrointestinal cancer [57], liver resection [54], knee arthroplasty [56], laparoscopic gynecology [53], bariatric [58] and endoscopic skull base surgery [59]. Studies have shown that recovery after carrying out robot-assisted radical prostatectomy occurs in a shorter time [55]. In addition, treatments can be carried out through telesurgery by incorporating AI, 5G-tactile internet, and fog computing [32]. Equally well, deep learning can be implemented in robotic surgery for solving inverse kinematics of the spatial snake-like robot [57], showing good performance in accuracy and speed. Additionally, deep learning has been
Fig. 2 Example of COVID-19 forecast layout

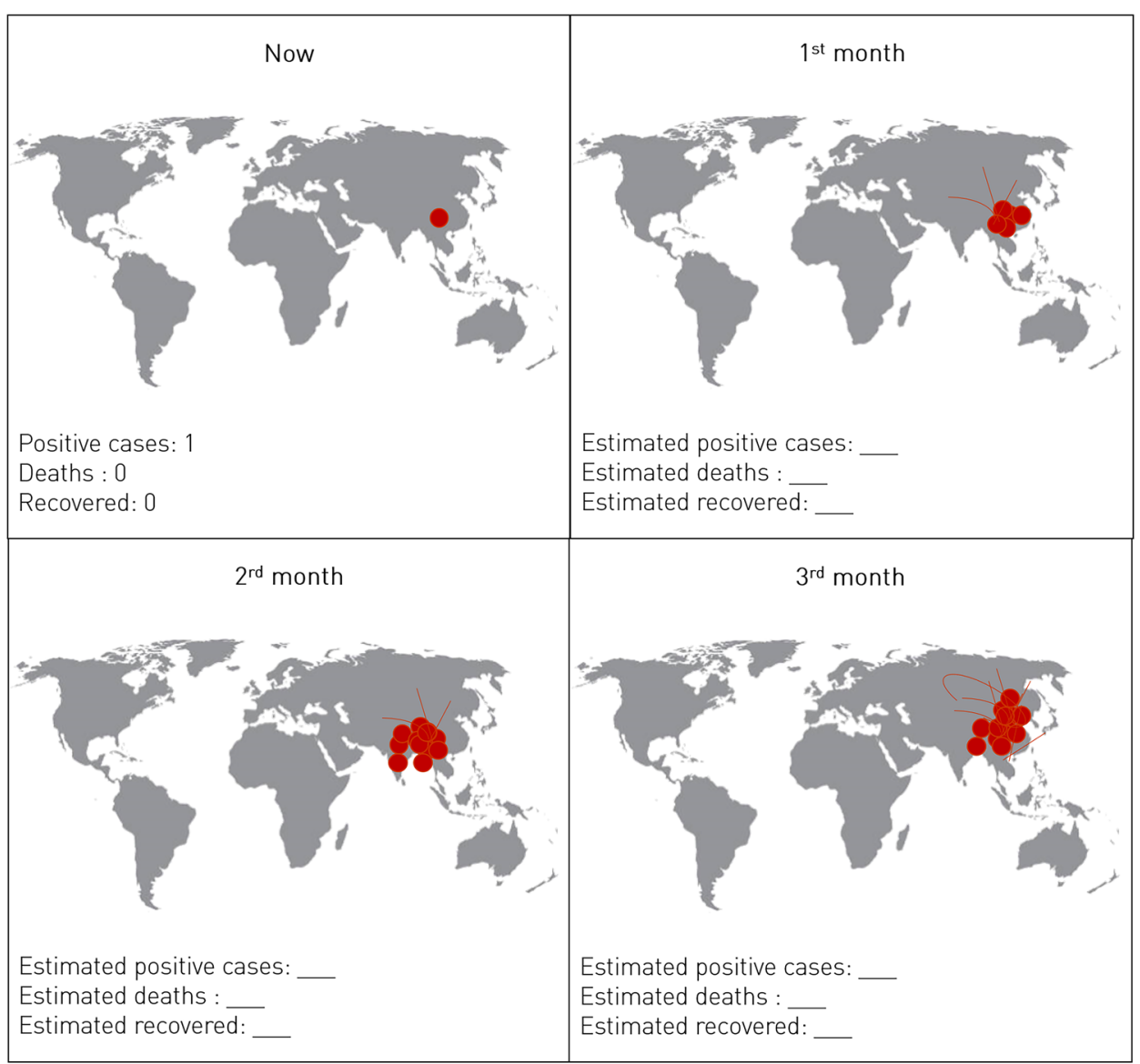


Fig. 3 Health 4.0 workflow for monitoring systems

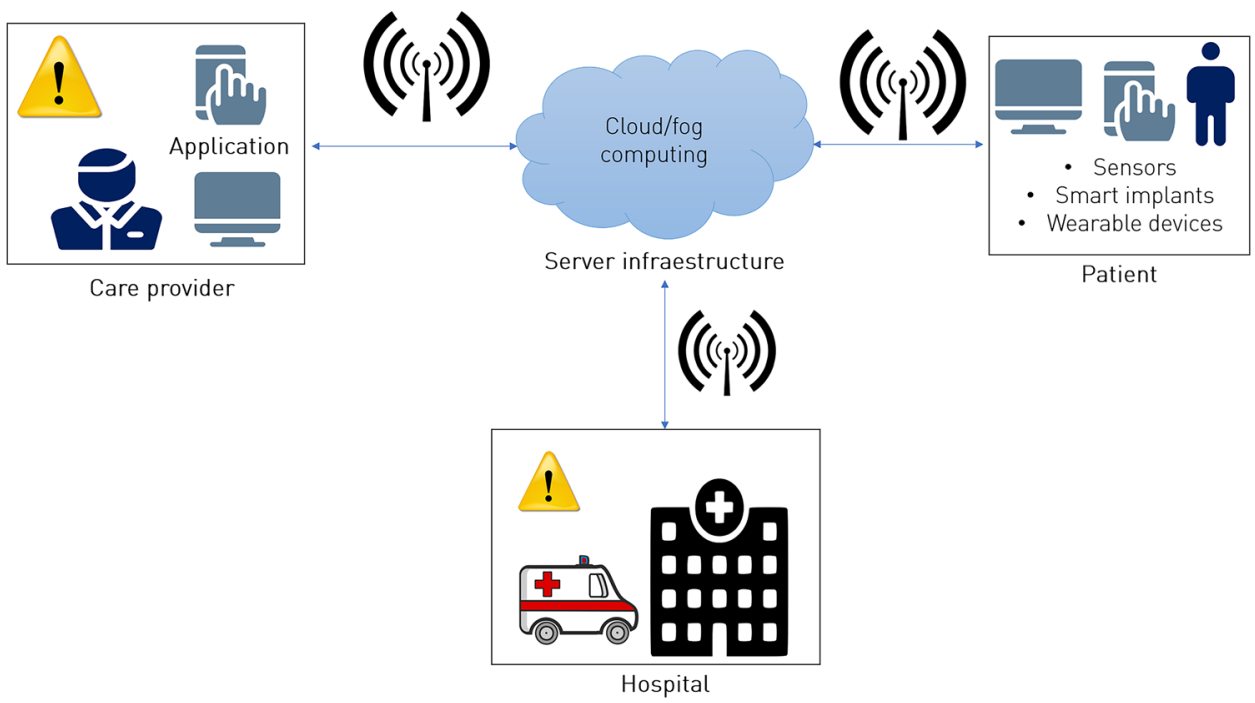

applied to carry out the recognition of surgical activities (such as the detection of tools and people) in videos captured in the operating room $[60,61]$, hence it improves the surgeon's control capabilities [61].

\subsection{Remote clinical services}

Advances in telecommunications such as $5 \mathrm{G}$ network [7, 26, 32], 6G network [12], tactile internet [32]), wearable devices $[26,31]$ and sensor networks [62] make remote clinical services telemedicine feasible and useful even in remote places [32]. Telemedicine services help to decrease the risk of contagion of COVID-19 [7, 10, 25, 63] by reducing the number of people who need to attend the hospital [12, 64].

Telemedicine is successful in both emergencies and routine check-ups [10]. Telemedicine has applications in teledentistry [11], remote care [6, 12], routine monitoring $[6,65]$, consultations $[2,7,66]$, electronic prescriptions [10], chatbots [67], tactile/haptic robots [12], telesurgery [12], medical drones [2, 17], telenursing [7], managing stress [68] and symptom checking [2, 64]. Figure 3 illustrates the general Health 4.0 pipeline for monitoring systems interconnecting patients with healthcare providers and hospitals for continuous patient monitoring and generating alarms when they have a critical condition. Medical sensors can help to obtain information [34], such as the temperature of the patients [2]. In addition, smart implants allow the capture in real-time physical data within the body $[34,69]$ having therapeutic and diagnostic benefits in postoperative care and rehabilitation [70]. Smart implants have been used in corpectomy implants [70], postoperative evaluation in the spine [71], orthopedic surgery [70], joint replacement [69], fracture treatment [69], and fixation of spine [69].

\section{Scopes of Health 4.0}

In this section, we report the Health 4.0 tasks to face the COVID-19 emergency (Table 1). Figure 4 illustrates stakeholders, tasks, and technologies in Health 4.0. The integration of AI, computer vision, and other technologies offer great advantages in different tasks of Health 4.0, such as carry out health care in a more preventive, predictive, and personalized way $[24,27,72,73]$. Also, Health 4.0 connects patients with healthcare professionals even in remote places [32], improves collaboration using technology [24, 74], enhances health care [75], reduces the risk of infection [10, 25], and facilitates pandemic strategies [15]. Further, advances in AI, algorithms, 5G networks [7], 6G networks [12], cloud computing, IoT, mobile GIS [17], and computational power make it possible to develop near-real-time systems [17, 76], remote health monitoring [12, 77], and measurement of clinical parameters (i.e. temperature, heart rates, sugar levels, blood parameters) [2, 12, 78]. Furthermore, it is expected that in $2030 \mathrm{IoT}$ will be replaced by the Internet of Everything and that $6 \mathrm{G}$ technology offers global coverage with great importance in the healthcare market [12]. The $6 \mathrm{G}$ network coverage will be in space-air-water, therefore, it will have an important role in Health 4.0 [12].

Due to recommendations that patients with mild symptoms of COVID-19 be managed at home [2], Health 4.0 applications are a great alternative to offer remote services. Hence, health 4.0 has shown the potential to carry out assisted diagnosis, augmented environments, forecasts of COVID-19, medical robotics, and remote clinical services. Also, significant multinational collaboration has been shown between medical experts, epidemiological leaders, and data scientists [48]. Collaboration between health, government, and industry leaders has an important role in modeling 
Table 1 Health 4.0 tasks to face the COVID-19 pandemic

\begin{tabular}{|c|c|c|c|}
\hline Health 4.0 Tasks & COVID-19 pandemic problem & Potential solution & AI and technologies \\
\hline Assisted diagnosis & $\begin{array}{l}\text { Lack of specialized physicians in } \\
\text { remote places Partial or strict } \\
\text { quarantine }\end{array}$ & Automatic diagnosis [30] & $\begin{array}{l}\text { AI }[15,22,23,25,35,79] \\
\text { Cloud computing }[30] \\
\text { Deep learning }[30,36,37,79-83] \\
\text { Fog computing }[29,30] \\
\text { Machine learning }[15,36,84] \\
\text { Sensors [12] }\end{array}$ \\
\hline Augmented environments & $\begin{array}{l}\text { Contact restrictions Partial or strict } \\
\text { quarantine Online classes }\end{array}$ & $\begin{array}{l}\text { Lesion tracking Procedure planning } \\
\text { [41] } \\
\text { Simulation Telesurgery [12] } \\
\text { Training }[23,34,41]\end{array}$ & $\begin{array}{l}\text { AR and VR [23, 34] } \\
\text { Blockchain [33] } \\
\text { Computer Vision Haptic [12] } \\
\text { Holographic communication [12] } \\
\text { Kinect sensors Mobile computing } \\
\text { Vibrotactile gloves }\end{array}$ \\
\hline Forecasts of COVID-19 & $\begin{array}{l}\text { Generation of industry, school, and } \\
\text { government reopening strategies } \\
\text { COVID-19 case tracking }\end{array}$ & $\begin{array}{l}\text { Predict the outbreak }[25,46] \\
\text { Risk prediction }[2,15]\end{array}$ & $\begin{array}{l}\text { AI }[2,15,25] \\
\text { Deep learning [47] } \\
\text { Drone-borne cameras [15] } \\
\text { Mobile GIS [17] } \\
\text { Machine learning [17] } \\
\text { NLP [17] } \\
\text { Portable digital recorders [15] } \\
\text { Smartphone applications [15] }\end{array}$ \\
\hline Medical robotics & Contact restrictions & $\begin{array}{l}\text { Ambulance robots [85] } \\
\text { Assisted surgery [57] } \\
\text { Nursing [85] } \\
\text { Receptionist robots [85] } \\
\text { Robotic based treatment }[34] \\
\text { Sterilization in surfaces }[2,85] \\
\text { Telesurgery [26, 32] } \\
\text { Tracking of surgical activities [60, } \\
\text { 61] }\end{array}$ & $\begin{array}{l}\text { 5G-tactile internet [32] } \\
\text { AI [32] } \\
\text { Deep learning [14, 57, 61] } \\
\text { Laser printing Machine learning } \\
\text { Robotics }[32,34]\end{array}$ \\
\hline Remote clinical services & $\begin{array}{l}\text { Partial or strict quarantine Lack of } \\
\text { specialized physician in remote } \\
\text { places }\end{array}$ & $\begin{array}{l}\text { COVID-19 symptom studies [48] } \\
\text { Electronic prescriptions [10] } \\
\text { Gather information [86] } \\
\text { Health monitoring [26, 28, 31] } \\
\text { Holographic communication [12] } \\
\text { Medical drones [2] } \\
\text { Postoperative evaluation [71] } \\
\text { Rehabilitation [26] } \\
\text { Remote surgery [12] } \\
\text { Teledentristy [11] } \\
\text { Transfer packages [86] } \\
\text { Virtual care platform [15] }\end{array}$ & $\begin{array}{l}\text { 5G [7, 31] and 6G [12] networks } \\
\text { AI [12] } \\
\text { Big data [31, 87] } \\
\text { Bluetooth [31] } \\
\text { Cloud computing [28] } \\
\text { Deep learning [12, 62] } \\
\text { Drones Fog computing [28, 29] } \\
\text { High-performance HTTP [31] } \\
\text { Machine learning [31] } \\
\text { Mobile apps [2] } \\
\text { NLP [67] } \\
\text { Sensor networks [62] } \\
\text { Smart thermometers [2] } \\
\text { Smartphone applications [11, 28] } \\
\text { Tactile internet [12] } \\
\text { Wearable devices [2, 12, 26, 28, 31, } \\
\text { 36, 48] } \\
\text { Wi-Fi hotspots [15] } \\
\text { Wireless telemetry }\end{array}$ \\
\hline
\end{tabular}

forecasts of COVID-19 [45]. Likewise, timely decisionmaking helps reduce the transmission rate [45]. The results obtained by COVID-19 prediction models can not only be applied in the health area, but also in the government and industry, to implement rapid response to outbreaks [45] and generate reopening strategies.

One of the interesting areas of assisted diagnosis is the detection of COVID-19 where respiratory symptoms, antibody studies, and biomedical imaging are mainly analyzed
[83]. In addition, studies have emerged based on the analysis of cough to detect COVID-19 [22]. Machine learning and deep learning approaches have shown applications in virus diagnosis [79], without manual feature extraction [83]. Table 2 reviews the AI techniques applied in the diagnosis of COVID-19 and the biomedical imaging analyzed, including CT and X-rays. Likewise, the results obtained are shown in terms of accuracy (ACC), area under the curve (AUC), sensitivity (RE), specificity (SP), and precision (PRE). 


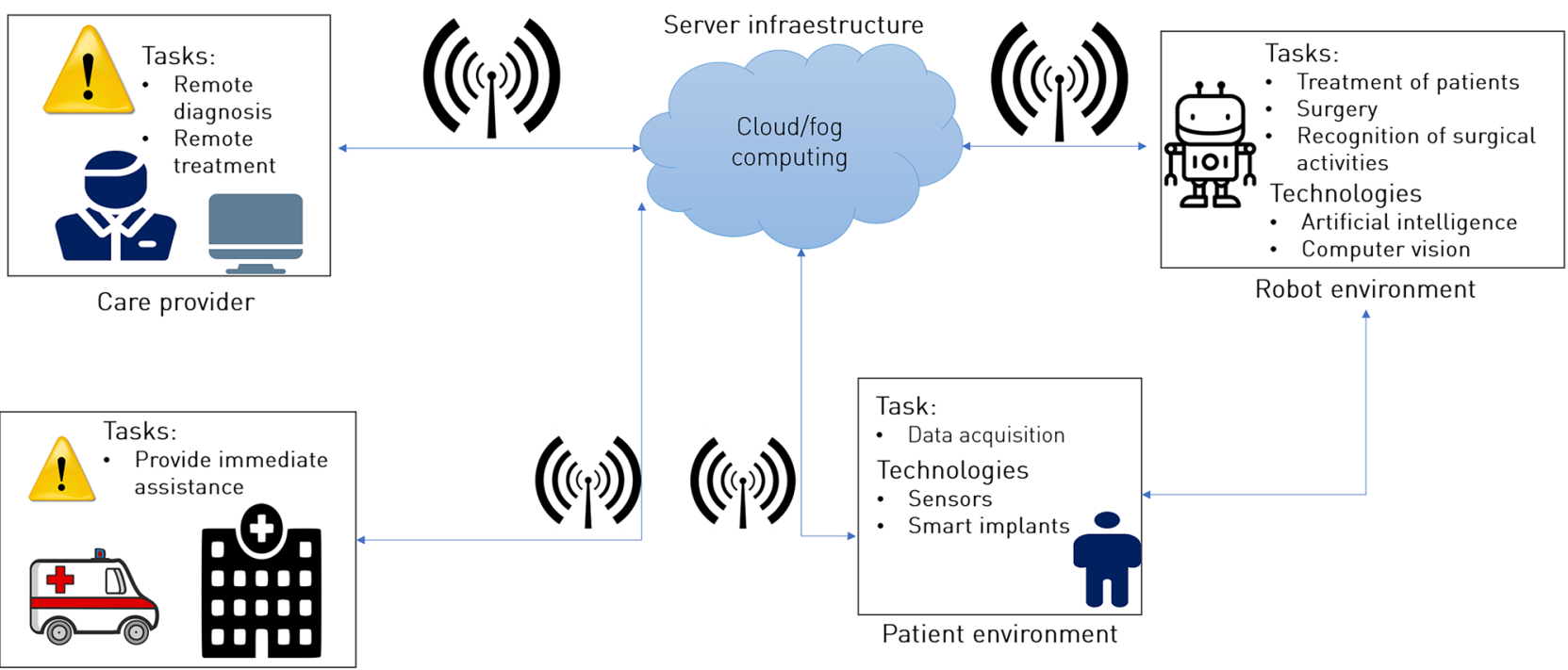

Hospital

Fig. 4 Stakeholders, tasks, and technologies in Health 4.0

\section{Challenges}

In the field of Health 4.0, the potential to face COVID19 has been shown. However, there are ethical [66], moral [10], technical, privacy [15], security [12, 23], and legal challenges. Also, to increase the acceptance of Health 4.0, it is necessary to adapt to the population, considering the culture and religious backgrounds of the users [10]. In the field of automatic diagnosis of COVID-19, more image datasets for screening need to be made publicly available, having a greater number of samples will help to develop more robust systems [80]. In Table 3, we show the challenges that exist in tasks of Health 4.0.
Table 2 AI techniques applied in the diagnosis of COVID-19

\begin{tabular}{|c|c|c|c|}
\hline AI field & Biomedical imaging & Techniques & Results \\
\hline \multirow[t]{14}{*}{ Deep learning } & \multirow[t]{5}{*}{$\mathrm{CT}$} & \multirow[t]{4}{*}{ Lesion-attention deep neural network [81] } & $88.6 \%$ ACC \\
\hline & & & $94 \%$ AUC \\
\hline & & & $88.8 \% \mathrm{RE}$ \\
\hline & & & 87.9\% PRE \\
\hline & & Multi-Task deep learning [80] & $98.78 \%$ ACC \\
\hline & \multirow[t]{9}{*}{$\mathrm{X}$-ray } & Deep transfer learning [88] & $98 \% \mathrm{RE} \pm 3$ \\
\hline & & & $90 \% \mathrm{SP}$ \\
\hline & & EfficientNet family of models [82] & $93.9 \%$ ACC \\
\hline & & & $96.8 \% \mathrm{RE}$ \\
\hline & & Faster R-CNN [83] & $97.36 \%$ ACC \\
\hline & & & $97.65 \% \mathrm{RE}$ \\
\hline & & & $99.28 \%$ PRE \\
\hline & & Inception V3 [16] & $>96 \% \mathrm{ACC}$ \\
\hline & & Multi-Task deep learning [80] & $84.67 \%$ ACC \\
\hline \multirow[t]{3}{*}{ Machine learning } & $\mathrm{CT}$ & Support Vector Machine [89] & $99.68 \%$ ACC \\
\hline & \multirow[t]{2}{*}{ X-ray } & Support Vector Machine [84] & $100 \%$ ACC \\
\hline & & Support Vector Machine [90] & $99.27 \% \mathrm{ACC}$ \\
\hline
\end{tabular}


Table 3 Health 4.0 tasks and challenges

\begin{tabular}{|c|c|}
\hline Health 4.0 Tasks & Challenges/needs \\
\hline Assisted diagnosis & $\begin{array}{l}\text { AI-based including machine learning and deep learning studies require a large amount of data to obtain reliable } \\
\text { performance }[15,37,88] \text {. } \\
\text { AI may not detect asymptomatic patients [23]. } \\
\text { Biomedical imaging for COVID-19 is expensive for those living in low-developing countries. }\end{array}$ \\
\hline Augmented environments & $\begin{array}{l}\text { AR and VR are still in development [12]. In addition, they need a large amount of data to provide excellent quality of } \\
\text { service [12]. } \\
\text { High cost of VR applications [23]. } \\
\text { Lack of experts for configuring VR [23]. }\end{array}$ \\
\hline Forecasts of COVID-19 & It is necessary to work on publicly available datasets, so that the studies can be validated by different researchers. \\
\hline Medical robotics & Robots need AC/DC power to ensure availability [85]. \\
\hline Remote clinical services & $\begin{array}{l}\text { Drones are exposed to hacking [23]. } \\
\text { Lack of direct communication can lead to mistrust in the patient [11]. } \\
\text { They need a high speed of network communication [12]. } \\
\text { Telesurgery is still an emerging field [12]. }\end{array}$ \\
\hline All tasks & $\begin{array}{l}5 \mathrm{G} \text { and } 6 \mathrm{G} \text { networks could be expensive in developing countries [23]. } \\
\text { AI algorithms that use large amounts of computational resources [12]. } \\
\text { Communication networks require a high level of security because the possible failure will impact the life of the } \\
\text { patient [12]. } \\
\text { It is necessary to redefine the business model in hospitals [12]. } \\
\text { Health data are sensitive personal data and require privacy measures [66]. }\end{array}$ \\
\hline
\end{tabular}

\section{Conclusions and future directions}

COVID-19 pandemic promotes disruption in different sectors of the population. This research analyzed Health 4.0 applications involving $\mathrm{AI}$ and communication technologies to be applied in assisted diagnosis, augmented environments, forecasts of COVID-19, medical robotics, and remote clinical services. Through the use of technologies such as $5 \mathrm{G} / 6 \mathrm{G}$ networks, cloud/fog computing, and tactile internet, can be carried out various complicated tasks such as near-real-time medical data collection, simulation tasks, and inter-connectivity with various sectors of medicine. Studies based on robotics and augmented reality emerge to improve health education in a less invasive and more interactive way. In addition, Health 4.0 will allow improving diagnosis and rehabilitation treatments. Conversely, there is still a long way to go in Health 4.0, areas of opportunity must be addressed, so that Health 4.0 can be applied not only in the COVID-19 pandemic, but also in future global viruses and natural disasters. Future research work should focus on:

- Carry out COVID-19 studies by cough analysis, to be able to carry out studies in countries that lack medical equipment such as CT scanners to perform virus studies.

- Develop AI techniques that use fewer computational resources.

- Include different sectors such as the medical, business, legal, and political sectors, to develop highly reliable health services using AI.

- Implement more personalized mobile applications according to the patient.

- Make more COVID-19 datasets publicly available.
- Optimize the electronic components of smart sensors. Also, look for ways to reduce costs, so that its use is feasible in semi-developed countries.

- Perform telesurgery studies using AI.

- Promote Health 4.0 services in developing countries.

Acknowledgements Consejo Nacional de Ciencia y Tecnología (CONACyT), Mexico.

Author contributions Cecilia-Irene Loeza Mejía: Conceptualization of this study, Investigation, Methodology, Writing - Original draft preparation. Eddy Sánchez-DelaCruz: Project administration, Supervision, Formal analysis, Writing- Original draft preparation. Pilar Pozos-Parra: Investigation, Methodology, Writing - Original draft preparation. Luis-Alfonso Landero-Hernández: Investigation, Methodology, Writing - Original draft preparation.

Funding Not applicable.

Data availability Not applicable.

Code availability Not applicable.

\section{Declarations}

Ethics approval Not applicable.

Consent to participate Not applicable.

Consent for publication Not applicable.

Conflicts of interest The authors declare that they have no conflict of interest. 


\section{References}

1. Sohrabi C, Alsafi Z, O’Neill N, Khan M, Kerwan A, Al-Jabir A, Iosifidis C, Agha R. World health organization declares global emergency: A review of the novel coronavirus (COVID-19). Int J Surg. 2020;76:71-6.

2. Chamola V, Hassija V, Gupta V, Guizani M. A comprehensive review of the COVID-19 pandemic and the role of IoT, drones, AI, blockchain, and $5 \mathrm{~g}$ in managing its impact. IEEE Access. 2020;8:90225-65.

3. Dehning J, Zierenberg J, Spitzner FP, Wibral M, Neto JP, Wilczek M, Priesemann V. Inferring COVID-19 spreading rates and potential change points for case number forecasts. medRxiv. 2020.

4. Frederico GF. Towards a supply chain 4.0 on the post-COVID-19 pandemic: a conceptual and strategic discussion for more resilient supply chains. Rajagiri Management Journal. 2021.

5. Cecilio-Fernandes D, Parisi MCR, Santos TM, Sandars J. The COVID-19 pandemic and the challenge of using technology for medical education in low and middle income countries. MedEdPublish 2020;9.

6. Jazieh AR, Kozlakidis Z. Healthcare transformation in the postcoronavirus pandemic era. Front Med. 2020;7:429.

7. Siriwardhana Y, Gür G, Ylianttila M, Liyanage M. The role of $5 \mathrm{~g}$ for digital healthcare against COVID-19 pandemic: Opportunities and challenges. ICT Express. 2020.

8. Chakraborty T, Ghosh I. Real-time forecasts and risk assessment of novel coronavirus (COVID-19) cases: A data-driven analysis. Chaos, Solitons \& Fractals. 2020;135:109850.

9. De Kock JH, Latham HA, Leslie SJ, Grindle M, Munoz S-A, Ellis L, Polson R, O'Malley CM. A rapid review of the impact of COVID-19 on the mental health of healthcare workers: implications for supporting psychological well-being. BMC Public Health. 2021;21(1):1-18.

10. Fagherazzi G, Goetzinger C, Rashid MA, Aguayo GA, Huiart L. Digital health strategies to fight COVID-19 worldwide: challenges, recommendations, and a call for papers. J Med Internet Res. 2020;22(6):e19284.

11. Ghai S. Teledentistry during COVID-19 pandemic. Diabetes \& Metabolic Syndrome: Clinical Research \& Reviews. 2020;14(5):933-5.

12. Nayak S, Patgiri R. 6 g communication technology: a vision on intelligent healthcare. In: Health Informatics: a Computational Perspective in Healthcare. Springer; 2021. p. 1-18.

13. Gerke S, Stern AD, Minssen T. Germany's digital health reforms in the COVID-19 era: lessons and opportunities for other countries. NPJ Digital Medicine. 2020;3(1):1-6.

14. Koppu S, Maddikunta PKR, Srivastava G. Deep learning disease prediction model for use with intelligent robots. Computers \& Electrical Engineering. 2020;87:106765.

15. Whitelaw S, Mamas MA, Topol E, Van Spall HG. Applications of digital technology in COVID-19 pandemic planning and response. The Lancet Digital Health. 2020.

16. Asif S, Wenhui Y. Automatic detection of COVID-19 using $\mathrm{X}$-ray images with deep convolutional neural networks and machine learning. medRxiv 2020.

17. Boulos MNK, Geraghty EM. Geographical tracking and mapping of coronavirus disease COVID-19/severe acute respiratory syndrome Coronavirus 2 (SARS-CoV-2) epidemic and associated events around the world: How 21 st century GIS technologies are supporting the global fight against outbreaks and epidemics. 2020.

18. Mahmoudi MR, Baleanu D, Mansor Z, Tuan BA, Pho K-H. Fuzzy clustering method to compare the spread rate of COVID19 in the high risks countries. Chaos, Solitons \& Fractals. 2020;140:110230.
19. Lau H, Khosrawipour V, Kocbach P, Mikolajczyk A, Schubert J, Bania J, Khosrawipour T. The positive impact of lockdown in Wuhan on containing the COVID-19 outbreak in china. J of Travel Med 2020;27(3):taaa037.

20. Zhuang Z, Cao P, Zhao S, Lou Y, Yang S, Wang W, Yang L, He D. Estimation of local novel coronavirus (COVID-19) cases in Wuhan, China from off-site reported cases and population flow data from different sources. Front Phys. 2020;8:336.

21. Kumar MS, Raut RD, Narwane VS, Narkhede BE. Applications of industry 4.0 to overcome the COVID-19 operational challenges. Diabetes Metab Syndr Clin Res Rev 2020;14(5):1283-1289.

22. Laguarta J, Hueto F, Subirana B. COVID-19 artificial intelligence diagnosis using only cough recordings. IEEE Open Journal of Engineering in Medicine and Biology. 2020;1:275-81.

23. Mbunge E, Akinnuwesi B, Fashoto SG, Metfula AS, Mashwama P. A critical review of emerging technologies for tackling COVID19 pandemic. Human Behavior and Emerging Technologies. 2021;3(1):25-39.

24. Bause M, Esfahani BK, Forbes H, Schaefer D. Design for health 4.0: Exploration of a new area. In: Proceedings of the Design Society: International Conference on Engineering Design, vol. 1. Cambridge University Press; 2019. p. 887-96.

25. Javaid M, Haleem A, Vaishya R, Bahl S, Suman R, Vaish A. Industry 4.0 technologies and their applications in fighting COVID-19 pandemic. Diabetes \& Metabolic Syndrome: Clinical Research \& Reviews. 2020;14(4):419-422.

26. Aceto G, Persico V, Pescapé A. Industry 4.0 and health: Internet of things, big data, and cloud computing for healthcare 4.0. J Ind Inf Integr. 2020;18:100129.

27. Chute, C., and French, T. Introducing care 4.0: An integrated care paradigm built on industry 4.0 capabilities. Int J Environ Res Public Health 2019;16(12):2247.

28. Jagadeeswari V, Subramaniyaswamy V, Logesh R, Vijayakumar $\mathrm{V}$. A study on medical internet of things and big data in personalized healthcare system. Health Information Science and Systems. 2018;6(1):1-20.

29. Kumari A, Tanwar S, Tyagi S, Kumar N. Fog computing for healthcare 4.0 environment: Opportunities and challenges. Comput Electr Eng 2018;72:1-13.

30. Tuli S, Basumatary N, Gill SS, Kahani M, Arya RC, Wander GS, Buyya R. Healthfog: An ensemble deep learning based smart healthcare system for automatic diagnosis of heart diseases in integrated iot and fog computing environments. Futur Gener Comput Syst. 2020;104:187-200.

31. Lloret J, Parra L, Taha M, Tomás J. An architecture and protocol for smart continuous ehealth monitoring using $5 \mathrm{~g}$. Comput Netw. 2017;129:340-51.

32. Tiwari K, Kumar S, Tiwari R. Fog assisted healthcare architecture for pre-operative support to reduce latency. Procedia Computer Science. 2020;167:1312-24.

33. Kothari P, Nuce M, Vasiliu-Feltes I, Hurley D, Fox M, Sneha S, Charles W, Nasr J, Iyengar R. Blockchain predictions for health care in 2021. Blockchain in Healthcare Today 2021.

34. Javaid M, Haleem A. Impact of industry 4.0 to create advancements in orthopaedics. Journal of Clinical Orthopaedics and Trauma. 2020;11:S491-S499.

35. Tian S, Yang W, Le Grange JM, Wang P, Huang W, Ye Z. Smart healthcare: making medical care more intelligent. Global Health Journal. 2019;3(3):62-5.

36. Qayyum A, Qadir J, Bilal M, Al-Fuqaha A. Secure and robust machine learning for healthcare: a survey. arXiv preprint arXiv: 2001.08103. 2020.

37. Ozturk T, Talo M, Yildirim EA, Baloglu UB, Yildirim O, Acharya UR. Automated detection of COVID-19 cases using deep neural networks with X-ray images. Comput Biol Med. 2020;121. 
38. McCarthy CJ, Uppot RN. Advances in virtual and augmented reality exploring the role in health-care education. J Radiol Nurs. 2019;38(2):104-5.

39. Sharma P, Vleugels RA, Nambudiri VE. Augmented reality in dermatology: Are we ready for ar? J Am Acad Dermatol. 2019;81(5):1216-22.

40. Kelly D, Hoang TN, Reinoso M, Joukhadar Z, Clements T, Vetere F. Augmented reality learning environment for physiotherapy education. Phys Ther Rev. 2018;23(1):21-8.

41. Ayoub A, Pulijala Y. The application of virtual reality and augmented reality in oral \& maxillofacial surgery. BMC Oral Health. 2019;19(1):1-8.

42. Balian S, McGovern SK, Abella BS, Blewer AL, Leary M. Feasibility of an augmented reality cardiopulmonary resuscitation training system for health care providers. Heliyon. 2019;5(8):e02205.

43. Mahmud N, Cohen J, Tsourides K, Berzin TM. Computer vision and augmented reality in gastrointestinal endoscopy. Gastroenterology report. 2015;3(3):179-84.

44. Grigoriadis N, Bakirtzis C, Politis C, Danas, K, Thuemmler C. Health 4.0: The case of multiple sclerosis. In: 2016 IEEE 18th International Conference on e-Health Networking, Applications and Services (Healthcom). IEEE; 2016. p. 1-5.

45. Cramer EY, Lopez VK, Niemi J, George GE, Cegan JC, Dettwiller ID, England WP, Farthing MW, Hunter RH, Lafferty B, et al. Evaluation of individual and ensemble probabilistic forecasts of COVID-19 mortality in the US. medRxiv. 2021.

46. Kafieh R, Arian R, Saeedizadeh N, Amini Z, Serej, ND, Minaee S, Yadav SK, Vaezi A, Rezaei N, Haghjooy Javanmard S. COVID-19 in Iran: Forecasting pandemic using deep learning. Comput Math Methods Med 2021;2021.

47. Zeroual A, Harrou F, Dairi A, Sun Y. Deep learning methods for forecasting COVID-19 time-series data: a comparative study. Chaos, Solitons \& Fractals. 2020;140:110121.

48. Drew DA, Nguyen LH, Steves CJ, Menni C, Freydin M, Varsavsky T, Sudre CH, Cardoso MJ, Ourselin S, Wolf J, et al. Rapid implementation of mobile technology for real-time epidemiology of COVID-19. Science. 2020;368(6497):1362-7.

49. Peng Y, Nagata MH. An empirical overview of nonlinearity and overfitting in machine learning using COVID-19 data. Chaos, Solitons \& Fractals. 2020;139:110055.

50. Shahid F, Zameer A, Muneeb M. Predictions for COVID-19 with deep learning models of 1stm, gru and bi-lstm. Chaos, Solitons \& Fractals. 2020;140:110212.

51. Yang Q, Yi C, Vajdi A, Cohnstaedt LW, Wu H, Guo X, Scoglio $\mathrm{CM}$. Short-term forecasts and long-term mitigation evaluations for the COVID-19 epidemic in Hubei Province, China. Infectious Disease Modelling. 2020;5:563-74.

52. Yeşilkanat CM. Spatio-temporal estimation of the daily cases of COVID-19 in worldwide using random forest machine learning algorithm. Chaos, Solitons \& Fractals. 2020;140:110210.

53. Moon AS, Garofalo J, Koirala P, Vu MLT, Chuang L. Robotic surgery in gynecology. Surg Clin. 2020;100(2):445-60.

54. Goja S, Yadav SK, Chaudhary RJ, Singh MK, Soin AS. Transition from open to robotic assisted liver resection: a retrospective comparative study. is experience of laparoscopic liver resections needed? Laparoscopic, Endoscopic and Robotic Surgery 2019;2(4):94-98.

55. Hakenberg OW. A brief overview of the development of robotassisted radical prostatectomy. Arab J Urol. 2018;16(3):293-6.

56. Naziri Q, Burekhovich SA, Mixa PJ, Pivec R, Newman JM, Shah NV, Patel PD, Sastry A. The trends in robotic-assisted knee arthroplasty: A statewide database study. J Orthop. 2019;16(3):298-301.

57. Omisore OM, Han S, Ren L, Elazab A, Hui L, Abdelhamid T, Azeez NA, Wang L. Deeply-learnt damped least-squares (dl-dls) method for inverse kinematics of snake-like robots. Neural Netw. 2018;107:34-47.
58. Pastrana M, Stoltzfus J, AlMandini A, El Chaar M. Evolution of outcomes of robotic bariatric surgery: first report based on mbsaqip database. Surg Obes Relat Dis. 2020;16(7):916-22.

59. Zappa F, Mattavelli D, Madoglio A, Rampinelli V, Ferrari M, Tampalini F, Fontanella M, Nicolai P, Doglietto F, Agosti E, et al. Hybrid robotics for endoscopic skull base surgery: preclinical evaluation and surgeon first impression. World Neurosurg. 2020;134:e572-80.

60. Padoy N. Machine and deep learning for workflow recognition during surgery. Minim Invasive Ther Allied Technol. 2019;28(2):82-90.

61. Zhao Z, Chen Z, Voros S, Cheng X. Real-time tracking of surgical instruments based on spatio-temporal context and deep learning. Computer Assisted Surgery. 2019;24(sup1):20-9.

62. Zhao R, Yan R, Chen Z, Mao K, Wang P, Gao RX. Deep learning and its applications to machine health monitoring. Mech Syst Signal Process. 2019;115:213-37.

63. Golinelli D, Boetto E, Carullo G, Landini MP, Fantini MP. How the COVID-19 pandemic is favoring the adoption of digital technologies in healthcare: a rapid literature review. MedRxiv 2020.

64. Monaghesh E, Hajizadeh A. The role of telehealth during COVID19 outbreak: a systematic review based on current evidence. BMC Public Health. 2020;20(1):1-9.

65. Kamal M, Aljohani A, Alanazi E. IoT meets COVID-19: Status, challenges, and opportunities. arXiv preprint arXiv:2007.12268. 2020.

66. Vokinger KN, Nittas V, Witt CM, Fabrikant SI, von Wyl V. Digital health and the COVID-19 epidemic: an assessment framework for apps from an epidemiological and legal perspective. Swiss Med Wkly. 2020;150:w20282.

67. Bharti U, Bajaj D, Batra H, Lalit S, Lalit S, Gangwani A. Medbot: Conversational artificial intelligence powered chatbot for delivering tele-health after COVID-19. In: 2020 5th International Conference on Communication and Electronics Systems (ICCES). IEEE; 2020. p. 870-75.

68. Keen SM, Roberts N. Preliminary evidence for the use and efficacy of mobile health applications in managing posttraumatic stress disorder symptoms. Health Systems. 2017;6(2):122-9.

69. O'Connor C, Kiourti A. Wireless sensors for smart orthopedic implants. Journal of Bio-and Tribo-Corrosion. 2017;3(2):20.

70. Ledet EH, Liddle B, Kradinova K, Harper S. Smart implants in orthopedic surgery, improving patient outcomes: a review. Innovation and Entrepreneurship in Health. 2018;5:41.

71. Ramakrishna VA, Chamoli U, Rajan G, Mukhopadhyay SC, Prusty BG, Diwan AD. Smart orthopaedic implants: A targeted approach for continuous postoperative evaluation in the spine. $\mathbf{J}$ Biomech. 2020;104:109690.

72. Andreu-Perez J, Leff DR, Ip HM, Yang G-Z. From wearable sensors to smart implants-toward pervasive and personalized healthcare. IEEE Trans Biomed Eng. 2015;62(12):2750-62.

73. Tortorella GL, Fogliatto FS, Mac Cawley Vergara A, Vassolo R, Sawhney R. Healthcare 4.0: trends, challenges and research directions. Prod Plan Control 2020;31(15):1245-1260.

74. Khelassi A, Estrela VV, Monteiro ACB, França RP, Iano Y, Razmjooy N, et al. Health 4.0: applications, management, technologies and review. Medical Technologies Journal 2019.

75. Lopes JM, Marrone P, Pereira SL, Dias EM. Health 4.0: Challenges for an orderly and inclusive innovation [commentary]. IEEE Technol Soc Mag 2019;38(3):17-19.

76. Roopaei M, Rad P, Jamshidi M. Deep learning control for complex and large scale cloud systems. Intelligent Automation \& Soft Computing. 2017;23(3):389-91.

77. Xu B, Xu L, Cai H, Jiang L, Luo Y, Gu Y. The design of an $\mathrm{m}$-health monitoring system based on a cloud computing platform. Enterprise Information Systems. 2017;11(1):17-36.

78. Kamišalić A, Fister I, Turkanović M, Karakatič S. Sensors and functionalities of non-invasive wrist-wearable devices: a review. Sensors. 2018;18(6):1714. 
79. Sufian A, Ghosh A, Sadiq AS, Smarandache F. A survey on deep transfer learning to edge computing for mitigating the COVID-19 pandemic. J Syst Archit. 2020;108:101830.

80. Alom MZ, Rahman M, Nasrin MS, Taha TM, Asari VK. COVID_mtnet: COVID-19 detection with multi-task deep learning approaches. arXiv preprint arXiv:2004.03747. 2020.

81. Liu B, Gao X, He M, Lv F, Yin G. Online COVID-19 diagnosis with chest CT images: Lesion-attention deep neural networks. medRxiv 2020.

82. Luz E, Silva PL, Silva R, Silva L, Moreira G, Menotti D. Towards an effective and efficient deep learning model for COVID-19 patterns detection in $\mathrm{x}$-ray images. arXiv preprint arXiv:2004.05717. 2020.

83. Shibly KH, Dey SK, Islam MT-U, Rahman MM. COVID faster r-cnn: A novel framework to diagnose novel coronavirus disease (COVID-19) in X-ray images. Informatics in Medicine Unlocked. 2020;20:100405.

84. Tuncer T, Dogan S, Ozyurt F. An automated residual exemplar local binary pattern and iterative relieff based COVID-19 detection method using chest x-ray image. Chemom Intell Lab Syst. 2020;203:104054.
85. Khan ZH, Siddique A, Lee CW. Robotics utilization for healthcare digitization in global COVID-19 management. Int J Environ Res Public Health. 2020;17(11):3819.

86. Hentati AI, Fourati LC. Comprehensive survey of UAVS communication networks. Computer Standards \& Interfaces 2020;103451.

87. Snyder M, Zhou W. Big data and health. The Lancet Digital Health. 2019;1(6):e252-4.

88. Minaee S, Kafieh R, Sonka M, Yazdani S, Soufi GJ. DeepCOVID: Predicting COVID-19 from chest $x$-ray images using deep transfer learning. Med Image Anal. 2020;65:101794.

89. Barstugan M, Ozkaya U, Ozturk S. Coronavirus (COVID-19) classification using CT images by machine learning methods. arXiv preprint arXiv:2003.09424. 2020.

90. Toğaçar M, Ergen B, Cömert Z. COVID-19 detection using deep learning models to exploit social mimic optimization and structured chest $\mathrm{x}$-ray images using fuzzy color and stacking approaches. Comput Biol Med. 2020;121:103805.

Publisher's Note Springer Nature remains neutral with regard to jurisdictional claims in published maps and institutional affiliations. 